\title{
Optimal Monetary Policy with Endogenous Export Participation*
}

\section{Dudley Cooke Co $^{\dagger}$}

\section{University of Exeter}

\begin{abstract}
This paper studies two often cited benefits of international monetary cooperation - lower inflation and increased international trade. I embed a model of endogenous export participation due to per period export costs within a standard monetary model of the business cycle. Endogenous export participation has two implications: policy competition between countries is more aggressive and the welfare gain from cooperation is magnified. Because high inflation also acts to raise firm export costs monetary cooperation offers an alternative explanation for rising numbers of exported products.
\end{abstract}

JEL Classification: E31, E52, F41

Keywords: Export Participation, Optimal Monetary Policy, Working Capital

*I thank seminar participants at Bristol and Lille Universities. I also thank Lise Patureau for comments. I am very grateful to the research department of the Bank of Portugal for providing financial support.

$\dagger$ Department of Economics, University of Exeter, Streatham Court, Rennes Drive, Exeter EX4 4PU, United Kingdom. Email: d.cooke@exeter.ac.uk 


\section{Introduction}

The benefits of international monetary cooperation have attracted considerable attention. In this paper, I develop a simple monetary model with endogenous export participation due to per period export costs and study optimal monetary policy. I show that endogenous export participation is a source of policy competition between countries. Policy competition leads to inflation and raises the costs for firms of financing working capital. High inflation also discourages export participation so that monetary cooperation offers an alternative explanation for rising numbers of exported products.

I consider a world economy with two countries. Each country is specialized in producing one good. Firms within a country differ in their productivity, produce a differentiated variety, and compete in a monopolistically competitive market. Labor is used for production and firms fund working capital - which is complementary to labor - by borrowing from financial intermediaries. ${ }^{1}$ Entry into the export market is subject to a per period cost. In this setting, higher borrowing costs deter exporting because they also raise export costs. When deciding on monetary policy, each government must therefore consider how it's policy decision affects the allocation of resources across firms and the extent of trade in varieties between countries.

Without international trade (autarky) each government attempts to stimulate economic activity and raise output by lowering the interest rate. The Friedman rule is optimal. When all varieties are traded there is potential for policy competition between countries because each government can raise welfare by manipulating the terms of trade in their favor. However, this can only achieved by inflating and reducing own output, creating a policy trade-off which depends on the monopoly distortion in supply. ${ }^{2}$ When export participation is endogenous there is an additional incentive to engage in policy competition

\footnotetext{
${ }^{1}$ See Christiano et al. (2011) and Jermann and Quadrini (2012) for a discussion of the importance of working capital for the analysis of monetary policy and the business cycle, respectively.

${ }^{2}$ It should be clear that with a relatively high distortion, the welfare gains from influencing the terms of
} 
because the output effect on the terms of trade depends on the number of varieties a country exports. When governments account for this additional distortion policy competition is more aggressive and inflation is higher.

The endogenous export participation channel that generates increased policy competition also has implications for the welfare gains from monetary cooperation. High inflation leads to reduced export participation. Inflation therefore also reduces the number of (imported) varieties available to the consumer. Since monetary cooperation results in the low inflation with high export participation the welfare gain from the reduction in inflation is magnified. Qualitatively, I show that the magnification effect is greater the higher is export participation. The magnification effect is important quantitatively. A calibration exercise shows that when annual inflation is around $9 \%$ the welfare loss is over $2 \%$ of consumption.

This paper is closely related to research that seeks to understand the reasons for systematic inflation when countries interact. For example, Cooley and Quadrini (2003) argue that policy competition between countries generates significant welfare losses at around $1 \%$ of annualized consumption. However, Arseneau (2007) shows that sufficiently large monopoly distortions can generate policies that coincide with the cooperative outcome (eliminating any welfare gains from cooperation). ${ }^{3}$ In this context, endogenous export participation is relevant because it mitigates the effects of domestic market distortions on policy decisions. Policy competition is more pervasive and more costly. Because monetary coordination leads to falling inflation and increased export participation, this paper also jointly addresses - from a welfare perspective - two often cited benefits of international monetary cooperation.

trade are outweighed by the inefficiencies associated with higher long-run inflation, and the Friedman rule remains optimal. In this sense, optimal policy is 'inward looking'.

${ }^{3}$ The natural alternative - summarized in Corsetti et al. (2011) - which focuses on short-run stabilization policies argues that the benefits of monetary cooperation are generally small. However, Cooley and Quadrini (2003) also show that the welfare benefits of reduced inflation dominate those associated with losing the ability to react optimally to shocks. 
The remainder of the paper is organized as follows. Section 2 discusses empirical motivation. Section 3 develops a two-country monetary model with endogenous export participation. In sections 4 and 5 the model solution is presented and optimal non-cooperative policy the welfare loss from non-cooperation are analyzed. Section 6 concludes.

\section{Empirical Motivation}

In this section I discuss the empirical motivation for the model developed below. I assume firms fund working capital requirements by borrowing from financial intermediaries. Higher interest rates depress economic activity due to increased costs associated with the use of productive inputs. In the presence of export costs higher interest rates also discourage firms from entering the export market. A main finding is that without international monetary cooperation interest rates are above the Friedman rule. With cooperation, interest and inflation rates are lower, output is higher, and a greater number of firms export their product.

I consider the case of Portugal (for which firm-level data is available). Portugal joined the Exchange Rate Mechanism of the European Monetary System and signed the Maastricht treaty - which included an explicit commitment to reduce inflation and interest rates - in 1992. In 1999 it adopted the Euro as it's national currency. In the top panel of figure 1, below, I plot an index for the total number of exporting firms per year for the period 1991-2004 alongside an index of gross domestic product. In the bottom panel I plot the annualized inflation and nominal interest rates over the same period. ${ }^{4}$

\footnotetext{
${ }^{4}$ Firm-level data on export participation is from the Portuguese census (INE). I use the transaction-level trade data available for the period 1991-2004 from customs declaration forms processed by INE. Interest rate and inflation rate data are from the OECD (MEI) and data on GDP is from the Penn World Tables. Comparable firm-level trade data for French manufacturing firms (for 1990-2007) is used (albeit for different purposes) by di Giovanni et al. (2011). Hummels et al. (2011) analyze Danish manufacturing firms (for 1995-2006). Both countries signed the Maastricht treaty in 1992, but whilst France adopted the Euro in 1999, Denmark remains pegged to the Euro, via ERM-II. Prior to 1999 both Denmark and France had
} 


\section{$====$ Figure 1 Here $====$}

During the 1990s, a period of rapidly increasing international monetary cooperation, Portugal benefited from a substantial reduction in inflation and nominal interest rates. At the same time the number of exporting firms rose continuously. It is important to note that the rise in export participation of Portuguese firms is unlikely the result of falling trade costs. A series of year-on-year tariff reductions were implemented when Portugal joined the European Union in 1986, but these ended in 1991-1992 (see Handley and Limao, 2012).

The theory behind the expansion in the number of exporting firms in this paper is based on monetary cooperation and a reduction in the financing costs of exporting. Bergin and Lin (2012) discuss the rise in the number of exported products across the EU during the same period I consider. They develop a model in which monetary union is equivalent to a future anticipated drop in trade costs, or a 'news-shock'. They also provide empirical evidence that extensive margins of exports across the EU (measured as the entry of new goods categories based on NBER-UN world trade data) responded aggressively prior to the adoption of the Euro, which is taken as confirmation of the news-shock hypothesis. A similar persistent rise in the number of exporting firms is observed in the Portuguese data. The explanation I offer for this is that falling interest rates and rising export participation are the joint outcome of greater monetary coordination between countries.

Finally, there is a small literature on financial constraints and exporting decisions by firms. Chaney (2005) develops a model in which firms use external financing for domestic activities and internal funds to cover entry costs into foreign markets and in Manova (2011) exporters finance variable costs internally but need to use external finance for some fraction of a fixed cost; in obtaining outside finance firms pledge tangible assets as collateral. Both Chaney relatively low levels of annual inflation (under 4\%) with interest rates peaking in both countries during the early 1990 s at around $11 \%$. 
(2005) and Manova (2011) focus on the pattern of exports due to financial constraints. Industries in which there are greater financial constraints have less exporters. I focus on monetary policy and appeal to a simpler type of financial friction in which the nominal interest rate affects the demand for labor. In my model, high interest rate regimes (due to non-cooperative policy) are associated with low export participation.

\section{The World Economy}

The world economy consists of two identical countries; home and foreign. In each country there is a representative household which supplies labor and deposits cash with financial intermediaries. Consumption of home and foreign goods is subject to a cash-in-advance constraint. In each country a unit mass of firms produce differentiated products using labor. Firms are heterogenous in productivity, incur a per period cost of exporting, and borrow from financial intermediaries to fund working capital. Money supply is controlled through lump-sum transfers. Home consumption, output and the nominal price of the domestic output are denoted with h-subscripts. Foreign consumption, output and prices are denoted with f-subscripts. Asterisks denote foreign economy variables.

\subsection{Households Intratemporal Consumption}

Total home consumption is a composite of varieties of home and foreign goods,

$C_{t}=\left[\theta^{1-\xi}\left(\int_{0}^{1} c_{h, t}(a)^{\sigma} d a\right)^{\xi / \sigma}+(1-\theta)^{1-\xi}\left(\int_{\mathrm{N}_{t}^{\star}} c_{f, t}(a)^{\sigma} d a\right)^{\xi / \sigma}\right]^{1 / \xi}$

where $c_{h, t}(a)$ is the consumption of a home good and $c_{f, t}(a)$ is the consumption of a foreign good. Whilst all home goods are available to the home consumer the available mass of foreign goods is $\mathbf{N}_{t}^{\star}$. The elasticity of substitution between differentiated varieties is $1 /(1-\sigma)>1$, the elasticity of substitution across home and foreign goods is $1 /(1-\xi)>0$, and home-bias for goods is measured by $\theta \geq 1 / 2$. 
Household consumption is characterized by standard demand curves,

$c_{h, t}(a)=\theta\left(\frac{p_{h, t}(a)}{P_{h, t}}\right)^{-1 /(1-\sigma)}\left(\frac{P_{h, t}}{P_{t}}\right)^{-1 /(1-\xi)} C_{t}$

and,

$c_{f, t}\left(a^{\star}\right)=(1-\theta)\left(\frac{p_{f, t}(a)}{P_{f, t}}\right)^{-1 /(1-\sigma)}\left(\frac{P_{f, t}}{P_{t}}\right)^{-1 /(1-\xi)} C_{t}$

where $p_{h, t}(a)$ is the home currency of a home variety and $p_{f, t}\left(a^{\star}\right)$ is the home currency price of a foreign variety. Price indexes home and foreign goods are given by, $P_{h, t}=$ $\left(\int_{0}^{1} p_{h, t}(a)^{\sigma /(\sigma-1)} d a\right)^{(\sigma-1) / \sigma}$ and $P_{f, t}=\left(\int_{\mathrm{N}_{t}^{\star}} p_{f, t}(a)^{\sigma /(\sigma-1)} d a^{\star}\right)^{(\sigma-1) / \sigma} \cdot$ Finally,

$P \equiv\left[\theta P_{h, t}^{\xi /(\xi-1)}+(1-\theta) P_{f, t}^{\xi /(\xi-1)}\right]^{(\xi-1) / \xi}$

is the consumer price index $(\mathrm{CPI})$.

\subsection{Firm Pricing and Productivity Threshold}

Each firm faces a financing constraint in that current wages, $W_{t}$, are paid for with loans from financial intermediaries. Loans are made at the gross nominal interest rate, $R_{t}$, and are repaid at the end of the period. Firms produce without overhead costs and labor is the only factor of production. Exporting is costly because there are labor-intensive per period costs. For a firm with a linear technology and labor productivity $a$, profits from domestic sales can be written as, $\varphi_{h, t}(a)=\left(p_{h, t}(a)-W_{t} R_{t} / a\right) y_{h, t}(a)$. Profits from potential export sales are,

$\varphi_{h, t}^{\star}(a)=\left(e_{t} p_{h, t}^{\star}(a)-\frac{W_{t} R_{t}}{a}\right) y_{h, t}^{\star}(a)-F W_{t} R_{t}$

where $F \geq 0$ denotes the cost associated with exporting and $e_{t}$ is the nominal exchange rate. The nominal interest rate appears both in the term capturing the costs of production and the term capturing export costs because firms borrow the total wage bill. 
The firm maximizes discounted total profits, $E_{0} \sum_{t=0}^{\infty}\left(\beta^{t+1} / C_{t+1} P_{t+1}\right) \varphi_{t}(a)$, where $\varphi_{t}(a) \equiv$ $\varphi_{h, t}(a)+\varphi_{h, t}^{\star}(a)$, subject to the (home and foreign) demand for it's product, and goods market constraints, $y_{h, t}(a)=c_{h, t}(a)$ and $y_{h, t}^{\star}(a)=c_{h, t}^{\star}(a)$. The optimal prices chosen by the home firm for the home and foreign market are, $p_{h, t}(a)=W_{t} R_{t} / \sigma a$ and $p_{h, t}^{\star}(a)=p_{h, t}(a) / e_{t}$, where $\sigma<1$ is the inverse monopoly markup. Given the optimal pricing decisions of firms, there is a zero-profit, threshold level of productivity for exporting, denoted $a_{x, t}=$ $\inf \left\{a: \varphi_{h, t}^{\star}(a)>0\right\}$. The threshold level of productivity is characterized by,

$a_{x, t} \geq \frac{1}{\sigma}\left[\frac{F}{(1-\theta)(1-\sigma)}\right]^{(1-\sigma) / \sigma}\left(\frac{W_{t} R_{t}}{e_{t} P_{t}^{\star} C_{t}^{\star}}\right)^{1 / \sigma}\left(\frac{P_{t}^{\star}}{P_{h, t}^{\star}}\right)^{(\xi-\sigma) / \sigma(\xi-1)} C_{t}^{\star}$

When $F=0$, all firms export, and the threshold level of productivity is irrelevant.

\subsection{Productivity Draws and Aggregation}

Productivity is Pareto distributed, where $G(a)=1-a^{-\gamma}$ is the cumulative distribution function. ${ }^{5}$ Aggregate productivity is, $\mathrm{A} \equiv\left(\int_{1}^{\infty} a^{\sigma /(1-\sigma)} d G(\gamma)\right)^{(1-\sigma) / \sigma}$. The average productivity across exporting firms is, $\mathrm{a}_{t} \equiv\left\{\left[1-G\left(a_{x, t}\right)\right]^{-1} \int_{a_{x, t}}^{\infty} a^{\sigma /(1-\sigma)} d G(a)\right\}^{(1-\sigma) / \sigma}$, where $1-G\left(a_{x, t}\right)$ is the probability of exporting. Since $a$ is Pareto, aggregate productivity can also be written as, $\mathrm{A}=\{\gamma /[\gamma-\sigma /(1-\sigma)]\}^{(1-\sigma) / \sigma}$. The weighted-average productivity for exporting firms is then, $\mathrm{a}_{t}=\mathrm{A} a_{x, t}$, so that $\mathrm{a}_{t}$ is proportional to the endogenous productivity cutoff defined by equation (6).

I aggregate firm-level variables using productivity averages. For example, consider the domestic currency price of the domestic variety $a, p_{h, t}(a)$, and define the average price as, $\mathrm{p}_{h, t} \equiv p_{h, t}(\mathrm{~A})$. Using the price index, $P_{h, t}=\left(\int_{0}^{1} p_{h, t}(a)^{\sigma /(\sigma-1)} d a\right)^{(\sigma-1) / \sigma}$, where $p_{h, t}(a)=$ $W_{t} R_{t} / \sigma a$, we can write $\mathrm{p}_{h, t}=W_{t} R_{t} / \sigma \mathrm{A}$, where $\mathrm{A}$ is defined above. This average price is

\footnotetext{
${ }^{5}$ The parameter $\gamma$ indexes the dispersion (of productivity) and characterizes firm-level heterogeneity and $a>1$ (the minimum productivity draw is 1 ).
} 
linked to the consumer price, $P_{h, t}$. In this case, because there are a measure one of firms, $P_{h, t}=\mathrm{p}_{h, t}$. Thus aggregation is applied to all firm-level variables.

\subsection{Household Financial Deposits and Labor Supply}

Household intertemporal utility is,

$\sum_{t=0}^{\infty} \beta^{t}\left[\ln \left(C_{t}\right)+\psi \ln \left(1-L_{t}\right)\right]$

where $L_{t}$ is the total supply of labor and $\beta \in(0,1)$ is the discount factor. ${ }^{6}$ The timing of events is based on the limited participation class of model, such as Christiano et al. (1997). At the beginning of a period, households deposit cash with domestic financial intermediaries. Any remaining cash is used for (total) consumption, subject to the following cash-in-advance constraint,

$P_{t} C_{t} \leq W_{t} L_{t}+M_{t}-D_{t}$

where $D_{t}>M_{t}$ are household deposits of cash with intermediaries and $W_{t} L_{t}$ is nominal labor income. The accumulation of cash (i.e., the cash the consumer has at the end-ofperiod $t$ /beginning-of-period $t+1)$ is,

$M_{t+1} \leq W_{t} L_{t}+D_{t} i_{t}+\varphi_{t}+\zeta_{t}-P_{t} C_{t}+M_{t}$

where $\zeta_{t}$ are profits of financial intermediaries and $i_{t}=R_{t}-1>0$ is the net nominal interest rate. Households maximize lifetime utility subject to these two constraints. The first-order conditions imply the following,

$w_{t}=\psi\left(\frac{C_{t}}{1-L_{t}}\right)$

$E_{t-1}\left[\frac{1}{P_{t} C_{t}}-\beta R_{t}\left(\frac{1}{P_{t+1} C_{t+1}}\right)\right]=0$

${ }^{6}$ This specification for preferences is a popular choice in the real business cycle literature and implies a Frisch elasticity of labor supply equal to one. 
where $w_{t} \equiv W_{t} / P_{t}$ is the real wage. The first expression is a condition for the labor-leisure trade-off. The second expression is an Euler equation in consumption. Household savings are made entirely through the domestic financial intermediary and the expectations term, $E_{t-1}$, appears in the Euler equation because household deposits with financial intermediaries are pre-determined.

\subsection{Equilibrium}

Financial intermediaries receive cash from households and from the government which total $D_{t}+T_{t}$. They make loans to firms at the net interest rate. At the end of the period, intermediaries pay interest on loans back to households, so the total amount households receive at the end of the period is, $R_{t}\left(T_{t}+D_{t}\right)$, and the profit of financial intermediaries is, $\zeta_{t}=R_{t} T_{t}$. Equilibrium in the financial sector is such that, $W_{t} L_{t}=D_{t}+T_{t}$, and when the government has access to lump-sum transfers and taxes, $T_{t}=g M_{t}$, where $1+g \equiv M_{t+1} / M_{t}$ is the rate of money growth.

Resource use (labor) in the economy can characterized as,

$\mathrm{A} L_{t}=\left[\theta\left(\frac{P_{t}}{P_{h, t}}\right)^{1 /(1-\xi)} C_{t}+(1-\theta)\left(\frac{e_{t} P_{h, t}^{\star}}{P_{h, t}}\right)\left(\frac{P_{t}^{\star}}{P_{h, t}^{\star}}\right)^{1 /(1-\xi)} C_{t}^{\star}\right]+\mathrm{AN}_{t} F$

The first two terms on the right-hand side of equation (12) capture the use of labor for production (for the home and export market, respectively) and $\mathrm{N}_{t} F$ is the use of labor by firms to cover per period export costs. The term $e_{t} P_{h, t}^{\star} / P_{h, t}$ is law of one price gap and generated through the non-tradedness of goods produced by less profitable firms (with productivity below the threshold $a_{x, t}$ ). I discuss the significance of this gap below in the context of generating a wedge through which countries can behave strategically in terms of setting monetary policy.

There is no international trade in financial assets (financial autarky) and balanced trade 
holds each period. This implies,

$P_{t} C_{t}\left[1-\theta\left(\frac{P_{t}}{P_{h, t}}\right)^{\xi /(1-\xi)}\right]=(1-\theta)\left(\frac{P_{t}^{\star}}{P_{h, t}^{\star}}\right)^{\xi /(1-\xi)} e_{t} P_{t}^{\star} C_{t}^{\star}$

Equations (2)-(13) complete the description of the home economy with symmetric conditions for the foreign economy. Due to financial autarky the foreign equivalent to (13) is redundant.

\section{Model Solution}

In this section I characterize the solution of the model in terms of money growth rates; respectively $g$ and $g^{\star}$ for the home and foreign economies. I also take advantage of the following two definitions of relative prices:

$\rho_{t} \equiv \frac{P_{f, t}}{P_{h, t}} \quad$ and $\quad \Phi_{t} \equiv \frac{P_{t}}{P_{h, t}}=\left[\theta+(1-\theta) \rho_{t}^{\xi /(\xi-1)}\right]^{(\xi-1) / \xi}$

The first relative price, $\rho_{t}$, is the terms-of-trade (the relative price of imported goods at the consumer level) and $\Phi_{t}$ is the CPI to domestic deflator. ${ }^{7}$ Similar expression are defined for the foreign economy as, $\rho_{t}^{\star} \equiv P_{f, t}^{\star} / P_{h, t}^{\star}$ and $\Phi_{t}^{\star} \equiv P_{t}^{\star} / P_{f, t}^{\star}$.

These definitions are useful because they highlight the role of endogenous export participation in affecting relative prices. Consider the price of a home variety in terms of foreign currency, $p_{h, t}^{\star}(a)=p_{h, t}(a) / e_{t}$. Notice that whilst the (average) consumer price of home goods in home currency is $P_{h, t}=p_{h, t}(a)$ the average price of home goods in the foreign country is, $P_{h, t}^{\star}=\mathrm{N}_{t}^{\mu} P_{h, t} / e_{t}$, where $\mathrm{N}_{t}$, which is the mass of home exported products, appears in this expression because some varieties are not traded, and $\mu \equiv 1 / \gamma+(\sigma-1) / \sigma<0$. Nontradedness therefore generates a wedge in the relative price of imported goods (the terms of trade) via deviations in the law of one price. In this case, the terms of trade are related by $\rho_{t}=\rho_{t}^{\star}\left(\mathrm{N}_{t} \mathrm{~N}_{t}^{\star}\right)^{\mu}$. Since policy competition is characterized by manipulating the terms of

\footnotetext{
${ }^{7}$ When preferences are Cobb-Douglas (that is, $\xi \rightarrow 0$ ), we can still use these conditions, as $\Phi_{t}=\rho_{t}^{1-\theta}$ and $\Phi_{t}^{\star}=\rho_{t}^{\star \theta-1}$.
} 
trade, the extent of non-tradedness affects the extent of competition depending on the size of $1 / \mathrm{N}_{\mathrm{t}}$ and $\mu$.

Making use of the definitions in (14), table 1 presents the key conditions for the world economy which solve for $\left\{C_{t}, L_{t}, \mathrm{~N}_{t}, \rho_{t}, R_{t}\right\}$ and their foreign counterparts in terms of $g$ and $g^{\star}$.

\section{$====$ Table 1 Here $====$}

where $v \equiv\left\{\frac{1-\theta}{F \sigma /(1-\sigma)}\left[\frac{\gamma-\sigma /(1-\sigma)}{\gamma}\right]^{1 / \sigma}\right\}^{(1-\xi) / \alpha}$ and $\alpha \equiv \frac{\xi}{\gamma}+\frac{\sigma-\xi}{\sigma}$. The stock of financial assets held by households in domestic financial intermediaries, denoted by $\bar{d} \equiv D_{t} / M_{t}$, is decided upon at the end of the period. Because households wait until the end of the following period before changing their deposits monetary policy generates a liquidity effect. Both economies are closed when $\theta=1$, and expanding the money stock (which raises $g$ ), lowers the nominal interest rate, and stimulates economic activity. In this case, using the home economy cash-loans ratio, for example, $L_{t}=\left[\psi\left(\frac{1+g}{\bar{d}+g}\right)+1\right]^{-1} \cdot$ Moreover, it is immediate that $L_{t}$ and $R_{t}$ are uniquely related so that when the government changes the money stock it can be thought of as directly controlling the nominal interest rate.

In the open economy, and when the export decision is endogenous, the correspondence between interest rates and labor supply breaks down except in the special case of CobbDouglas preferences, where $\xi=0$ and $\alpha=1$. In the Cobb-Douglas case home and foreign nominal interest rates are also independent. ${ }^{8}$ We can focus on this special case to generate intuition for the effects of exogenous changes in monetary policy in an open economy. The basic mechanism is that a home monetary expansion stimulates the level of domestic activity via the terms of trade. However, because the cost of financing working capital is also lower,

\footnotetext{
${ }^{8}$ An important point that I discuss below is that with Cobb-Douglas preferences the trade share in output is fixed. Once we allow $\xi$ to differ from zero this is no longer true and interest rates are no longer independent.
} 
a greater proportion of firms enter the export market. In the foreign economy, the cost of working capital is unchanged, but the terms of trade move in the opposite direction. The impact of home policy on the foreign economy is to depress economic activity with a constant mass of foreign exporters.

Changes in the mass of exporters have an important impact on international relative consumer prices and feeds into the optimal policy decision of the government. In the open economy, the government faces a trade-off when setting policy between manipulating the terms of trade and reducing the monetary distortion generated by a positive nominal interest rate. In this model, the trade-off depends on the size of domestic monopoly distortion. If the monopoly distortion is high, policy becomes inward looking. However, when export participation is endogenous, the extent to which a one country's monetary policy affects the other countries terms of trade depends on the number of exported products. Endogenous exporting manifests itself in a law of one price gap at the consumer level and this acts to magnify policy competition between countries relative to the case when all firms export.

\section{Optimal Monetary Policy under Commitment}

I now consider optimal monetary policy under commitment when each government plays a static Nash game.

\subsection{Policy Constraints and Regimes}

In this section I generate policy constraints for the government and describe the policy problem. In particular, I describe the equilibrium using the conditions in table 1 in terms of real allocations only. The key step involves deriving $\Phi=\Phi\left(\mathrm{N}, \mathrm{N}^{\star}\right)$ which pins down international relative prices as a function of the mass of exported products from both economies. Eliminating the number of home exporters from home resources, total labor supplied can 
then be expressed as,

$L=\left[(\mu-1)-\kappa\left(\frac{\mathrm{N}}{\mathrm{N} \star 1-\mu}\right)^{\eta}\right] \mathrm{N} F / \mu$

where $\eta \equiv \xi /(1-\xi)$ and $\kappa \equiv \theta /(1-\theta)$. Given the definition of $\mu$ above, the first term in $[\ldots]$ in $(15)$ can be written as $\mu-1=[(\sigma-1) / \sigma]-[(\gamma-1) / \gamma]$. This expression has a natural interpretation because $\gamma /(\gamma-1)$ is the arithmetic mean of the Pareto distribution (recall, $G(a)=1-a^{-\gamma}$ is the density function) and the term $\frac{1}{\sigma}-1$ is the marginal utility gain from spreading a given amount of consumption on a basket with an additional variety in a symmetric equilibrium. Thus, $\mu-1$ captures 'heterogeneity-adjusted' love-of-variety. From the perspective of the home economy this only affects foreign products because all home products are available to the consumer. The second term is the ratio of exported products weighted by the relative openness of the home economy, $\kappa$. Notice that the ratio of exported products is only present when $\eta \neq 0$.

To solve for home consumption, I take the resource equation and use the export cut-off to eliminate exported products and relative prices. This implies,

$C=\mathrm{A} L\left[\kappa+\left(\frac{\mathrm{N}}{\mathrm{N} \star 1-\mu}\right)^{-\eta}\right]^{(1+\eta) / \eta}\left[\kappa+(1-\mu)\left(\frac{\mathrm{N}}{\mathrm{N} \star 1-\mu}\right)^{-\eta}\right]^{-1}$

Again, the ratio of exported products only appears in (16) when $\eta \neq 0$. Finally, there is an equivalent expression for $\Phi^{\star}$ and corresponding conditions for foreign labor supply and consumption.

When monetary policy is set non-cooperatively the problem for the home government is to pick $L \in(0,1), C$ and $\mathbf{N} \in(0,1)$, to maximize, $\ln (C)+\psi \ln (1-L)$. subject to (15) and (16) taking $\left\{L^{\star}, C^{\star}, \mathrm{N}^{\star}\right\}$ as given. When governments cooperate, a supranational agency maximizes a weighted average of home and foreign consumers utility. Specifically, the policy problem is to pick $\{L, C, \mathbf{N}\}$ and $\left\{L^{\star}, C^{\star}, \mathbf{N}^{\star}\right\}$ to maximize $(1 / 2) u(C, L)+(1 / 2) u\left(C^{\star}, L^{\star}\right)$, 
subject to the same constraints as the non-cooperative case, plus the foreign equivalents to (15) and (16).

When each government acts independently, the home government, for example, does not internalize the fact that relative international prices also depend on the level of foreign consumption and the mass of foreign exported products. Under cooperation, the supranational agency acts as if it were running a closed economy, and the impact of policy on relative prices, world consumption, and the mass of exported products is accounted for explicitly. Under cooperation, it is therefore optimal to eliminate the monetary and monopoly distortions. However, in an equilibrium with commitment, the government cannot eliminate the monopoly distortion, because there is a zero lower bound on the nominal interest rate. Because cooperation removes the channels that provide an incentive for each government to engage in policy competition the Friedman rule is optimal.

\subsection{Analytical Results for Cobb-Douglas Utility}

In this section I specialize the utility function such that $\eta=0$ and $\kappa=1$. This has two implications. First, it is possible to generate simple analytical expressions for inflation, the mass of exporters, and the welfare gain from cooperation. Second, policy can be characterized as the choice of interest rate. If one then interprets inflation as a trade cost (by raising the costs of financing working capital inflation raises the fixed costs of exporting) a rise in inflation drives low productivity firms out of the export market and the demand fulfilled previously by these firms is re-allocated to those remaining.

\subsubsection{Exporters and Inflation}

The policy problem reduces to picking $R \geq 1$ to maximize,

$\ln \left[\varkappa L(R)^{1 / 2}\left(L^{\star}\left(R^{\star}\right)^{1-\mu}\right)^{1 / 2}\right]+\psi \ln [1-L(R)]$ 
taking $R^{\star} \geq 1$ as given where $\mu<0$ and $\varkappa=\mathrm{A}(1-\mu / 2)^{\mu / 2-1}(-\mu / F 2)^{-\mu / 2}>0$ are parameters. Using the first-order condition along with (15), the mass of exporters under optimal policy can be written as a function of the structural parameters of the model,

$$
\mathbf{N}=\frac{[\gamma(1-\sigma)-\sigma] / F}{(1+2 \psi)[\gamma(1+\sigma)-\sigma]}
$$

It is immediate from this condition that the mass of home exporters is decreasing in $\sigma$ and increasing in $\gamma$. Recall that a higher $\sigma$ translates into a higher elasticity of substitution between varieties of goods. This implies firms charge a lower markup which makes it less costly to inflate and reduce domestic production. A higher value for $\gamma$ means that firms are more homogenous. As firms are more homogenous a greater proportion of firms export. Notice that a change in the elasticity of substitution between varieties or dispersion of productivity in (18) has two effects because it changes the underlying mass of exporters, for a given policy (falling and raising, respectively), and it also changes the policy choice.

To net out the double-effect of changing $\sigma$ and $\gamma$ I consider the ratio of the mass of exporting firms under non-cooperation versus cooperation, given by $\left[\frac{2 \psi \gamma}{\gamma(1+\sigma)-\sigma}+1\right]\left(\frac{1}{1+2 \psi}\right)$. This statistic is less than one because more firms export under cooperation than when governments act independently. In contrast to (18) it is decreasing in both $\sigma$ and $\gamma$. This reflects the impact of policy competition on the optimal level of inflation and it is now clear that the more homogenous are firms, the more aggressive is policy, because the government has greater scope to manipulate the mass of exporters.

To pin-down inflation I use the steady-state consumption Euler equation. This implies,

$$
\pi=\beta\left[1+\frac{\sigma}{\gamma /(\gamma-1)}\right] \quad ; \quad \gamma=\frac{1}{s . d .}+\frac{\sigma}{1-\sigma}
$$

where $\pi \equiv P / P_{-1}-1$ is inflation and s.d. is the standard deviation of output. Under these conditions, there is always policy competition between countries and inflation is function of monopolistic competition, productivity dispersion, and the discount factor. Consistent 
with the analysis above, policy competition is more aggressive, and inflation higher, for two reasons: when domestic competition is greater (higher $\sigma$ ) it is less costly to use inflation to reduce output and manipulate the terms of trade and as productivity is less dispersed, and firms are more concentrated round the minimum productivity draw (higher $\gamma$ or lower s.d.), each government has a greater incentive to use inflation to reduce the number of exporters because this boosts the output effect on the terms of trade $(\partial \pi / \partial \gamma>0)$. Finally, we can see that less productive economies, as measured by $\mathrm{A} \geq 1$ (the average economy-wide level of productivity), have higher inflation, since $A$ is decreasing in both parameters.

\subsubsection{Welfare}

I define the welfare loss associated with not cooperating by the additional consumption required to make individuals equally well-off under cooperative or non-cooperative policy. Taking advantage of the function form of utility, the welfare loss can be written as, $\mathcal{L}=$ $[C(\mathrm{c}) / C(\mathrm{n})]\{[1-L(\mathrm{c})] /[1-L(\mathrm{n})]\}^{\psi}-1$, where $C(\mathrm{c})$ and $C(\mathrm{n})$ are the allocations of consumption in each regime, i.e., cooperative or competitive, and $C=\varkappa L^{1 / 2} L^{\star(1-\mu) / 2}$. The welfare loss is then, $\mathcal{L}=[L(\mathrm{c}) / L(\mathrm{n})]^{1-(\mu / 2)}\{[1-L(\mathrm{c})] /[1-L(\mathrm{n})]\}^{\psi}-1$. Since $\mu<0$ it is clear that, relative to the case where all products are exported, the loss is greater, for a given value of $L(\mathrm{c}) / L(\mathrm{n})$. However, with Cobb-Douglas preferences, the value of $L(\mathrm{n})$ is the same regardless of whether or not export participation is endogenous. Since inflation is higher it follows that the ratio $L(\mathrm{c}) / L(\mathrm{n})$ is greater. The conclusion from this is that when export participation is endogenous the welfare loss from non cooperation is greater than when export participation is given both because policy competition is more aggressive and because this leads to a drop in the number of varieties available to the consumer.

I now write the welfare loss as a function of the underlying parameter values and inflation:

$\mathcal{L}=(\pi / \beta)^{1-\mu / 2}\left[\frac{1+2 \psi}{(\pi / \beta)+2 \psi}\right]^{1+\psi-\mu / 2}-1$ 
Equation (20) is necessarily an increasing function of inflation, but holding inflation constant, we can write, $\partial \mathcal{L} / \partial \mu \approx-\frac{1}{2} \ln \{(1+2 \psi) /[1+2 \psi(\pi / \beta)]\}>0$, where $\partial \mu / \partial \gamma<0$ and $\partial \mu / \partial \sigma>0$. Since inflation is increasing in both $\sigma$ and $\gamma$ equation (20) shows how endogenous export participation generates a magnification effect onto the welfare loss from non-cooperation. Finally, note that with all products traded the loss is given by, $\mathcal{L}=(\pi / \beta)\{(1+2 \psi) /[(\pi / \beta)+2 \psi]\}^{1+\psi}-1 .^{9}$ This expression is decreasing in $\sigma$ because inflation is increasing in $\sigma$. When all goods are traded this expression captures the trade-off faced when inflating via only a reduction in own output.

I focus on export participation (the extensive margin) as a measure of international trade. With Cobb-Douglas preferences the volume of exports (the intensive margin) is a constant share of output. Assuming a fixed mass of exporters, monetary cooperation must also leads to an expansion in the volume of trade. In that sense, the mechanism that generates inflation in this model works alongside a more standard one. However, the magnified gains from trade that arise when export participation is endogenous in this model are not due to a rise in economy-wide the level of technology. Rather, it is possible to generate a larger welfare gain from a given change in the terms of trade when more firms export. This dual role for policy in affecting the margins of trade results in a direct (via inflation) and indirect (via traded products) welfare implications.

\subsection{CES Utility}

I now consider CES utility. Unlike the Cobb-Douglas case, in which it is possible to characterize monetary policy in each country by the nominal interest rate (indeed, nominal interest rates are independent), under CES preferences I solve the governments optimization problem choosing allocations subject to the constraints (15) and (16) .

\footnotetext{
${ }^{9}$ Now we require $\sigma>1 / 2$ to generate a welfare loss, because only then will governments choose to engage policy competition.
} 


\subsubsection{Exporters and Inflation}

Using the first-order conditions for the governments optimization problem optimal policy generates the following non-linear expression for the number of exporters,

$$
\left(1-\frac{1 / F}{\mathrm{~N}}\right)\left(\frac{\mu}{1+\kappa \mathrm{N}^{\mu \eta}}\right)-\psi\left[1+\frac{(1-\mu)}{(1+\eta) \kappa \mathrm{N}^{\mu \eta}}\right]=1
$$

where I have imposed the equilibrium condition that $\mathbf{N}=\mathbf{N}^{\star}$. Equation (21) generalizes (18) with the extent of non-linearity controlled through $\eta>-1$ and $\mu<0$, where $\mu$ depends on both the extent of firm-level heterogeneity and monopolistic competition. Under plausible calibrations $\mu \eta$ is close to zero, and so (21) is always close to being linear, with a unique solution for $\mathbf{N} \in(0,1)$. This is confirmed in the numerical analysis below.

It is further possible to write inflation as a function of the mass of exported products. In particular,

$\pi=\frac{\beta \sigma}{\psi}\left[1+\frac{\mu}{\left(1-\mu+\mathrm{N}^{\mu \eta}\right)} \frac{1 / F}{\mathrm{~N}}\right]\left(\frac{\mu}{1+\mathrm{N}^{\eta}}-1\right)$

Note that setting $\eta=0$ in (21) and (22) generates (19) when $\kappa=1$. In general, there is no explicit solution for inflation available in the CES case and from inspection it is difficult to determine how changes in the elasticity of substitution alter policy competition. However, there are two benchmarks results one can consider. Faia and Monacelli (2004) study Ramsey monetary policy in a two-country model with sticky-prices. In their model, a higher elasticity of substitution between home and foreign goods raises the incentive for the government to engage in policy competition in an attempt to generate a relative appreciation of its own residents' purchasing power. The value of $\eta$ matters because it determines expenditure switching. In Cooley and Quadrini (2003), however, a lower elasticity (between intermediate inputs) generates greater policy competition because real appreciations generate a positive effect on domestic production. They assume flexible prices.

\subsubsection{Calibration}


I calibrate the model under the assumption that countries cooperate. I consider three values for the elasticity of substitution between home and foreign goods, given by $1 /(1-\xi)$. The first is analyzed in section 5.2, namely Cobb-Douglas preferences, where $\xi=0$. The other elasticities I assume are 0.85 and 1.2. Both values are common in business cycle analysis and consistent with aggregate estimates for trade elasticities. ${ }^{10}$ Alongside the trade elasticity, I assume the elasticity of substitution between varieties of goods (given by $1 /(1-\sigma)$ ) is 7. Finally consumers allocate $20 \%$ of their consumption expenditure to varieties originating from abroad which implies setting $\kappa=4$. These parameters determine consumer preferences, as given by equation (1).

Following Bernard et al. (2003) the benchmark calibration for the standard deviation of output is 1.67. This statistic is given by $1 /\left[\gamma+\left(\frac{\sigma}{\sigma-1}\right)\right]$ and implies setting $\gamma=6.6$. I then calibrate the fixed cost of exporting and the weight attached to the utility of leisure given by $F$ and $\psi$ - to match two statistics. First, I use fixed costs so that $17 \%$ of firms export (this further implies that, on average, exporters are $31 \%$ more productive than nonexporters). I then use the weight attached to the utility of leisure so that individuals spend $30 \%$ of their time endowment working. Finally, I vary the standard deviation of output over the following values; s.d. $=\{1,2,5\}$. For each case I consider, I re-calibrate $F$ and $\psi$ so that labor supply and the mass of exporting firms are constant across all specifications.

\subsubsection{Quantitative Results}

In this section I quantify the annual rate of inflation and welfare loss from non-cooperation. I determine optimal policy when countries act independently by solving (21) numerically.

\footnotetext{
${ }^{10} \mathrm{~A}$ standard measure in business cycle analysis is 1.5 (Chari et al. (2002)). However, this applies to a model with only traded goods. Devereux and Hnatkovska (2012) calibrate a similar model to that studied here and assume an elasticity of substitution for traded and non-traded goods below one. Bodenstein (2011) discusses the assumption of distribution costs in non-traded goods to obtain a low implied elasticity of substitution between traded goods. Also see Corsetti et al. (2008) who suggest an elasticity of 0.85 .
} 
The aim is two-fold; first I show how varying the elasticity of substitution affects policy competition between countries, and second, I do this for differing degrees of firm-level heterogeneity. In table 2, I present the annualized rate of inflation and associated welfare loss from non-cooperation for the different specifications.

\section{$====$ Table 2 Here $====$}

The welfare loss from non-cooperation in the benchmark case with Cobb-Douglas preferences $5.6 \%$ of annual steady state consumption with an annual inflation rate of $25.6 \%$. Varying firm-level heterogeneity by changing the standard deviation of output over the range specified above only affects the inflation rate by 2 percentage points. In this case, although endogenous export participation generates policy competition and inflation changes in firmlevel heterogeneity are of limited impact. Finally, in the benchmark Cobb-Douglas case, adding 1 percentage point to inflation raises welfare losses relative to cooperation by around $0.22 \%$.

As discussed above, a limitation of Cobb-Douglas preferences is that they imply a constant trade share. If we interpret lower inflation as a change in trade costs then it seems likely that the share of output in trade will also rise along with the mass of exporting firms. This suggests an elasticity greater than one is more appropriate. ${ }^{11}$ Assuming an elasticity of 1.2 generates $9.1 \%$ annual inflation, a figure is similar to that reported in section 2 for Portugal at the beginning of the 1990's. Despite the reduction in inflation the welfare loss from non-cooperation is large at $2.3 \%$. The alternative possibility; that bundles are compliments in utility, generates far higher inflation rates with comparable welfare losses.

\footnotetext{
${ }^{11}$ Note that because the elasticity of intratemporal substitution exceeds the elasticity of intertemporal substitution (which is set at one) home and foreign bundles are substitutes.
} 
There are two papers to which these simple quantitative results can be compared. Arseneau (2007) assumes Cobb-Douglas preferences and focuses on the role of imperfect competition in eliminating welfare gains from cooperation. In his analysis anticipated inflation distorts the consumption-leisure margin. This generates large welfare gains because inflation alters the terms of trade through the relative price of leisure, which acts as a non-traded good. ${ }^{12}$ Cooley and Quadrini (2003) allow anticipated inflation to affect the terms of trade through the relative price of intermediate inputs into production. In the baseline calibration of their model, the annual inflation rate is just over 3\%. However, because firms produce goods under perfect competition there is no trade-off between the terms of trade and the domestic monopoly distortion.

\section{Conclusion}

This paper studies two of the most often cited benefits of monetary cooperation - lower inflation and increased international trade. It focuses on the role of the extensive margin of trade using a stylized model with firm-level heterogeneity. Without international coordination, inflation discourages export participation because it raises the costs of financing working capital. By removing the potential for policy competition, coordination generates lower inflation with more firms entering the export market.

\footnotetext{
${ }^{12} \mathrm{~A}$ second potential difficulty in making a comparison with the results here is that country size determines home-bias in consumption. The case of symmetric countries in Arseneau (2007) corresponds to the analysis of section 5.2.
} 


\section{References}

ARSENEAU, D. (2007), "The Inflation Tax in an Open Economy with Imperfect Competition", Review of Economic Dynamics 10, 126-147.

BERGIN, P. and LIN, C. (2012), "The Dynamic Effects of a Currency Union on Trade", Journal of International Economics 87, 191-204.

BERNARD, A., EATON, J., JENSEN, B. and KORTUM, S. (2003), "Plants and Productivity in International Trade", American Economic Review 93, 1268-1290.

BODENSTEIN, M. (2011), "Closing Large Open Economy Models", Journal of International Economics 84, 160-177.

CHARI, V., KEHOE, P. and MCGRATTEN, E. (2002), "Can Sticky Prices Generate Volatile and Persistent Real Exchange Rates?", Review of Economic Studies 69, 633-63.

CHANEY, T. (2005), "Liquidity Constrained Exporters", mimeo.

CHRISTIANO, L., TRABANDT, M. and WALENTIN, K. (2011), "DSGE Models for Monetary Policy", in the Handbook of Monetary Economics edited by Benjamin M. Friedman and Michael Woodford, Volume 3B, Elsevier.

COOLEY, T. and QUADRINI, V. (2003), "Common Currencies versus Monetary Independence", Review of Economics Studies 70, 785-806.

CORSETTI, G., DEDOLA, L. and LEDUC, S. (2008), "International Risk Sharing and the Transmission of Productivity Shocks", Review of Economic Studies 75, 443-473.

CORSETTI, G., DEDOLA, L. and LEDUC, S. (2011), "Optimal Monetary Policy in Open Economies", in the Handbook of Monetary Economics edited by Benjamin M. Friedman and Michael Woodford, Volume 3B, Elsevier.

CORSETTI, G. and PESENTI, P. (2001), "Welfare and Macroeconomic Interdependence", Quarterly Journal of Economics 116, 421-46. 
DEVEREUX, M. and HNATKOVSKA, V. (2012), "The Extensive Margin, Sectoral Shares and International Business Cycles", Canadian Journal of Economics 45, 509-534.

GHIRONI, F. and MELITZ, M. (2005), "International Trade and Macroeconomic Dynamics with Heterogeneous Firms", Quarterly Journal of Economics 120, 865-915.

di GIOVAnNI, J., LEVCHENKO, A. and MEJEAN, I. (2011), "Firms, Destinations, and Aggregate Fluctuations", mimeo.

FAIA, E. and MONACELLI, T. (2004), "Ramsey Monetary Policy and International Relative Prices", International Finance Discussion Papers 798, Board of Governors of the Federal Reserve System.

HANDLEY, K. and LIMAO, N. (2012), "Trade and Investment under Policy Uncertainty: Theory and Firm Evidence", NBER working paper 17790.

HUMmELS, D., JORGENSEN, R., MUNCH, R. and XIANG, C. (2011), "The Wage Effects of International Offshoring: Evidence from Danish Matched Worker-Firm Data", NBER Working Paper No. 17496.

JERMANN, U. and QUADRINI, V. (2012), "Macroeconomic Effects of Financial Shocks", American Economic Review 102, 238-271.

MANOVA, K. (2011), "Credit Constraints, Heterogeneous Firms, and International Trade", mimeo.

MELITZ, M. (2003), "The Impact of Trade on Intra-Industry Reallocations and Aggregate Industry Productivity", Econometrica, 71, 1695-1725. 
Figure 1: Exporting Firms, Inflation and Interest Rates
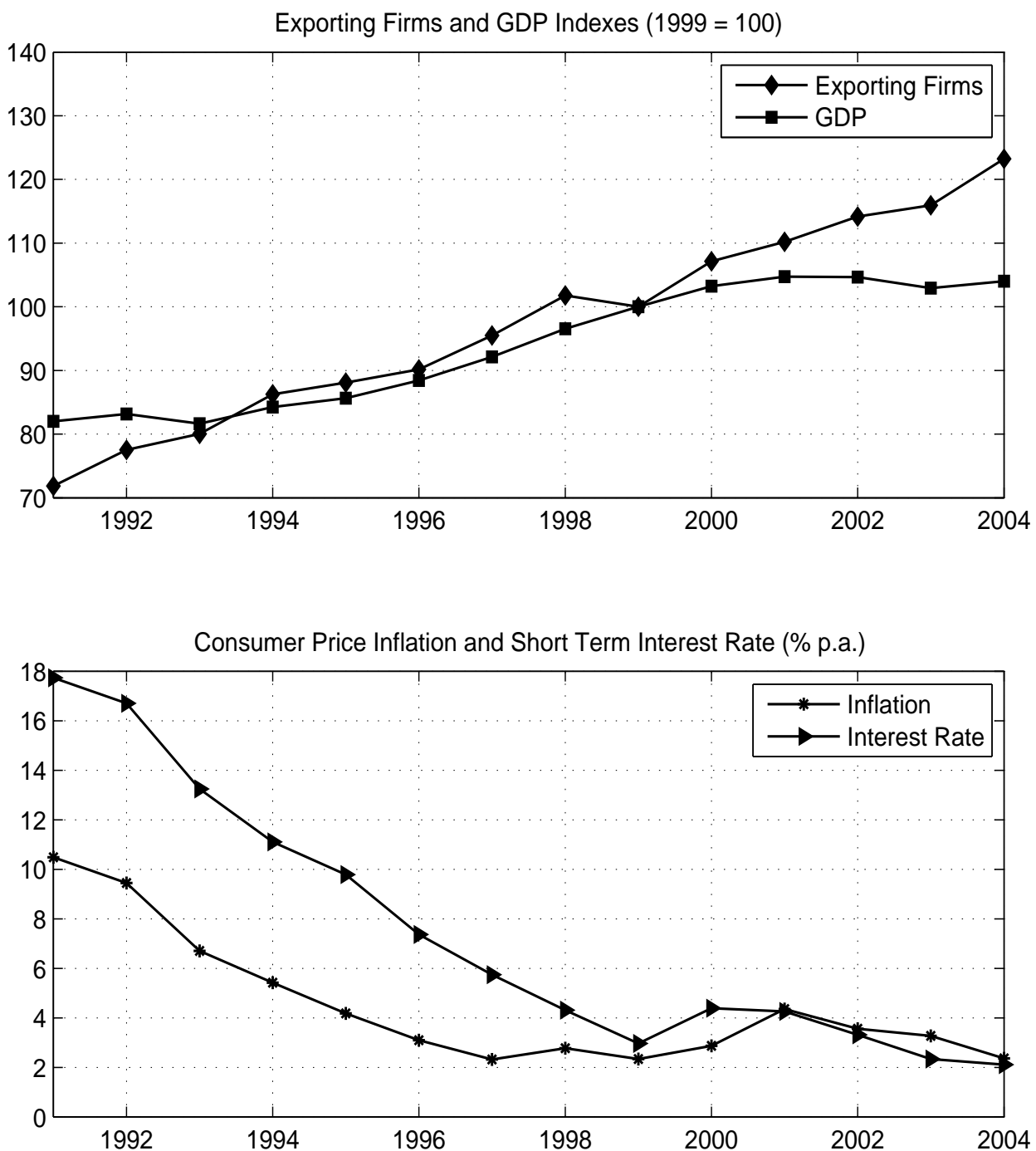
Table 1: Model Equations

\begin{tabular}{l|cc}
\multicolumn{2}{c}{ Home } & Foreign \\
\hline \hline Resources & $\mathrm{A} L_{t}=\Phi_{t} C_{t}+\mathrm{AN}_{t} F$ & $\mathrm{~A} L_{t}^{\star}=\Phi_{t}^{\star} C_{t}^{\star}+\mathrm{AN}_{t}^{\star} F$ \\
Labor Market & $\sigma \mathrm{A}\left(1-L_{t}\right)=\psi \Phi_{t} R_{t} C_{t}$ & $\sigma \mathrm{A}\left(1-L_{t}^{\star}\right)=\psi \Phi_{t}^{\star} R_{t}^{\star} C_{t}^{\star}$ \\
Cash-to-Loans & $1 / L_{t}=1+\psi(1+g) /(\bar{d}+g)$ & $1 / L_{t}^{\star}=1+\psi\left(1+g^{\star}\right) /\left(\bar{d}+g^{\star}\right)$ \\
Exporters & $\mathrm{N}_{t}=v\left(\rho_{t} \Phi_{t}^{\star} C_{t}^{\star 1-\xi} / \mathrm{N}_{t}^{\star \mu}\right)^{1 / \alpha}$ & $\mathrm{N}_{t}^{\star}=v\left(\mathrm{~N}_{t}^{\star \mu} \Phi_{t} C_{t}^{1-\xi} / \rho_{t}\right)^{1 / \alpha}$ \\
\hline \hline Relative Prices & $\rho_{t}=\rho_{t}^{\star}\left(\mathrm{N}_{t} \mathrm{~N}_{t}^{\star}\right)^{\mu}$ \\
Balanced Trade & $\mathrm{N}_{t}^{\star \mu} \Phi_{t} C_{t}\left[1-\theta \Phi_{t}^{\xi /(1-\xi)}\right]=(1-\theta)\left(\rho_{t}^{\star} \Phi_{t}^{\star}\right)^{\xi /(1-\xi)} \rho_{t} \Phi_{t}^{\star} C_{t}^{\star}$ \\
\hline \hline
\end{tabular}


Table 2: Inflation and Welfare Loss without Monetary Cooperation

\begin{tabular}{l|cccc}
\multicolumn{1}{c}{ Firm Heterogeneity } & 1 & 1.67 & 2 & 5 \\
\hline \hline & \multicolumn{4}{c}{$1 /(1-\xi)=1.2$} \\
\hline Inflation & $9.5 \%$ & $9.1 \%$ & $8.9 \%$ & $8.6 \%$ \\
Welfare Loss & $2.4 \%$ & $2.3 \%$ & $2.1 \%$ & $2.0 \%$ \\
\hline & \multicolumn{5}{c}{$1 /(1-\xi)=1$} \\
\hline Inflation & $26.4 \%$ & $25.6 \%$ & $25.3 \%$ & $24.5 \%$ \\
Welfare Loss & $5.8 \%$ & $5.6 \%$ & $5.4 \%$ & $5.3 \%$ \\
\hline \multirow{4}{*}{$1 /(1-\xi)=0.85$} \\
\hline Inflation & $43.1 \%$ & $42.1 \%$ & $41.5 \%$ & $40.5 \%$ \\
Welfare Loss & $9.5 \%$ & $9.1 \%$ & $8.9 \%$ & $8.8 \%$ \\
\hline \hline
\end{tabular}

